\title{
BIOPOLÍTICA, BIOPODER E CUIDADO DE SI NA CAMPANHA ANTITABAGISTA DAS EMBALAGENS DE CIGARRO
}

\author{
Claudemir Sousa \\ Universidade Federal da Paraíba \\ João Pessoa, PB, BR. \\ Regina Baracuhy ${ }^{* *}$ \\ Universidade Federal da Paraíba \\ João Pessoa, PB, BR.
}

\begin{abstract}
Resumo
Este artigo discute a constituição do sujeito fumante em campanhas antitabagistas presentes nos enunciados que circulam na materialidade sincrética das embalagens de cigarro. Refletiremos sobre duas dimensões que envolvem o corpo desse sujeito, considerado uma superfície discursiva onde incidem relações de saber/poder: o corpo investido pelos biopoderes, através dos quais se promove a biopolítica da população, e o corpo como um domínio da estética de si, para refletirmos sobre o cuidado e o governo de si. Utilizamos a teoria da Análise do Discurso, mobilizando como categorias analíticas as noções-conceitos foucaultianas de sujeito, governamentalidade, biopoder, biopolítica e cuidado de si. Metodologicamente, nossa análise possui uma abordagem qualitativa, de cunho descritivo-interpretativo, e recai sobre um corpus constituído por nove dos enunciados supracitados. Concluímos que nas campanhas antitabagistas cruzam-se os discursos médico, jurídico e estético, indicando formas de o sujeito cuidar de si, ao mesmo tempo em que deixa entrever um poder que visa gerir a vida da população com o objetivo final de torná-la mais produtiva e menos onerosa ao Estado.
\end{abstract}

Palavras-chave: Análise do Discurso; governamentalidade; campanhas antitabagistas.

\section{BIOPOLITICS, BIOPOWER AND SELFCARE IN ANTI-SMOKING CAMPAIGN ON CIGARETTE PACKS}

\begin{abstract}
This article discusses the constitution of the smoker subject in anti-smoking campaigns present in the statements molded over the syncretic materiality of cigarette packs. We reflect about two dimensions that involve the body of this subject, considered a discursive surface where knowledge/power relations operate: the body vested by the biopower, through which are promoted the biopolitics of the population, and the body as an aesthetic of self, in order to reflect about the care and the government of self. We use the theory of the Discourse Analysis, mobilizing Foucaultian concepts/notions of subject, governmentality, biopower, biopolitics and selfcare as analytical categories. Methodologically, our analysis has a qualitative approach with a descriptive and interpretative nature and draws on a corpus consisting of nine of the statements above. We conclude that the anti-smoking campaigns intersect medical, legal and aesthetic discourses, which indicate ways of taking care of oneself while also allowing a glimpse at a power that aims to manage people's lives with the ultimate goal of making them more productive and less costly to the State.
\end{abstract}

Keywords: Discourse Analysis; governmentality; anti-smoking campaigns.

\footnotetext{
"Claudemir Sousa é mestrando pelo Programa de Pós-Graduação em Linguística (PROLING) da Universidade Federal da Paraíba (UFPB) (2014-2015) e graduado em Letras pela Universidade Federal do Maranhão (2013). É membro do Círculo de Discussões em Análise do Discurso (CIDADI) e do Grupo de Pesquisa em Linguagem e Discurso do Maranhão (GPELD). Sua área de interesse é a Análise do Discurso, atuando principalmente com os seguintes temas: reflexões teóricas e analíticas sobre a Análise do Discurso, identidade, mídia e poder. Email: claudemir201089@hotmail.com.

${ }^{* *}$ Regina Baracuhy é Doutora em Linguística e Língua Portuguesa pela Universidade Estadual Paulista Júlio de Mesquita Filho (UNESP), Campus de Araraquara. Possui Graduação em Letras e Mestrado em Língua Portuguesa pela UFPB. Atualmente é professora da Universidade Federal da Paraíba, onde ministra disciplinas em nível de Graduação no Departamento de Letras Clássicas e Vernáculas (DLCV) e no PROLING. Também é Líder do Grupo de Pesquisa CIDADI. E-mail: mrbaracuhy@hotmail.com.
} 


\section{Considerações iniciais}

Este trabalho é resultante da pesquisa de Mestrado intitulada "Governamentalidade, Corpo e imagem: a constituição do sujeito fumante em campanhas antitabagistas nas embalagens de cigarro", desenvolvida no Programa de Pós-Graduação em Linguística (PROLING), da Universidade Federal da Paraíba (UFPB), cujo objetivo principal já se encontra no título: analisar a constituição do sujeito fumante em campanhas de prevenção ao tabagismo, a partir de enunciados que circulam na materialidade sincrética das embalagens de cigarro.

Nossa pesquisa ancora-se no arcabouço teórico da Análise do Discurso (AD) e suas ressonâncias no Brasil, pondo-a em diálogo com os trabalhos de Michel Foucault, para tratar dos modos de objetivação/subjetivação do sujeito fumante; com a Semiologia Histórica de JeanJacques Courtine, para analisar a materialidade sincrética dos enunciados e com alguns teóricos dos Estudos Culturais, tais como Stuart Hall e Tomaz Tadeu da Silva, para dar suporte às discussões sobre a construção de identidades para o sujeito fumante pelo e no discurso. Para este artigo, optamos por utilizar as noções-conceitos de sujeito, governamentalidade, biopoder, biopolítica e cuidado de si, de Foucault para conduzir nossas análises. $\mathrm{Na} \mathrm{AD}$, teoria e método não se separam; por isso as categorias teóricas são também analíticas.

Este trabalho se caracteriza metodologicamente por uma abordagem qualitativa do corpus, que tem como marca a interpretação. No Brasil há um arquivo constituído por vinte e nove enunciados antitabagistas inseridos em embalagens de cigarro durante os anos de 2001 a 2008.

Construímos um corpus composto por dezoito enunciados para análise, os quais foram coletados do site do Instituto Nacional do Câncer ${ }^{1}$ (INCA). Orientando-nos pelas regularidades discursivas (FOUCAULT, 2008) que os enunciados guardam entre si, nós os distribuímos em três séries enunciativas (FOUCAULT, 2008), construídas a partir da ideia de trajeto temático, uma noção metodológica desenvolvida por Guilhaumou e Maldidier (2010, p. 165) para caracterizar um conjunto de configurações textuais que, por meio de diferentes acontecimentos, associam certos temas e "inte- ressa-se pelo novo no interior da repetição". Assim, as séries construídas foram: os riscos do tabagismo à saúde do sujeito fumante; os riscos do tabagismo passivo à saúde; e tabagismo e impotência sexual. Para este artigo, apresentaremos a análise de nove enunciados pertencentes à primeira série citada acima.

Esta temática está na ordem do dia e constitui uma forma de gestão pública da saúde da população, credibilizada por discursos científicos e outros saberes. São os domínios da Medicina e do Direito que estabelecem práticas para os fumantes, possibilitando a elaboração de leis que determinam regras para o consumo do cigarro nos espaços públicos e privados. Com isso, mudam-se os hábitos dos sujeitos de forma minuciosa, até mesmo a relação de si para si, mediante o uso do que estamos chamando metodologicamente de dispositivo de combate ao tabagismo, partindo da noção de dispositivo de Foucault (2013b).

O discurso de combate ao tabagismo é atravessado por vários discursos, como o da Economia, Saúde, Política, Estética, Moral, etc., que incidem sobre os sujeitos e se materializam sob a forma de enunciados, indicando-nos formas de conduzir nossas vidas, de estabelecer práticas com nós mesmos, com nossos corpos e com os outros. Nossas discussões objetivam analisar como o sujeito fumante é constituído nesse discurso.

\section{AD: um campo de múltiplos diálogos}

A Análise do Discurso, que subsidia nossas análises, é um campo marcado por rupturas e deslocamentos. Na fase designada de terceira época da $\mathrm{AD}$ por Pêcheux (1990), o grupo em torno desse autor mudou os rumos de seus trabalhos, aproximando-se de historiadores da Nova História, ${ }^{2}$ o que possibilitou a presença de Foucault na AD, sobretudo por influência de Jean-Jacques Courtine. Os trabalhos da Nova História, ao invés do enfocar os grandes acontecimentos protagonizados por grandes homens, voltam-se para a "história vista de baixo" (BURKE, 2011, p. 13), mostrando que "o cotidiano também tem uma história" (Le GOFF 1994, p. 87) e nasce do desejo de contraporse à grande história para dar lugar aos homens infames (FOUCAULT, 2006, p. 211). 
Os reflexos disso na $\mathrm{AD}$ são mencionados por Pêcheux (2006) quando ele empreende uma reflexão a partir do enunciado "On a gagné" para discutir o entrecruzamento do acontecimento discursivo com a estrutura e do "batimento entre descrição e interpretação" a fim de reformular a noção de discurso, antes compreendido como efeito de sentido entre interlocutores, para "estrutura (língua) e acontecimento (história)". Gregolin (2004) cita também, como causas desse redirecionamento, as transformações políticas do Partido Comunista Francês, a crise do Marxismo, a fragmentação das esquerdas, a morte de Althusser, as revoluções audiovisuais, as transformações econômicas, a globalização e as novas relações de trabalho. A partir da percepção das novas discursividades na política, da necessidade de repensar o discurso em sua inscrição no acontecimento, Pêcheux opera deslocamentos em sua teoria, afastando-se das ideias de Althusser e passa a se ocupar também com os discursos que circulam em materialidades não-verbais.

Nesse quadro de transformações e rupturas, os trabalhos de Courtine trouxeram grandes contribuições para essa área, com a leitura que ele fez da $A r$ queologia do Saber (2008) de Michel Foucault, estabelecendo uma interlocução entre as ideias desse autor e a $\mathrm{AD}$ pecheutiana.

Após ter problematizado as mutações no discurso político, Courtine passou a empreender análises sobre as representações do rosto e da expressão em um campo denominado de Semiologia Histórica. ${ }^{3}$ Nos estudos do discurso, a história é inerente à produção e circulação discursiva e o enunciado é investigado no processo histórico de sua formação, o que justifica o termo Histórica ao lado de Semiologia.

Saussure apresenta a noção de Semiologia em passagens do Curso de Linguística Geral (CLG), em que ele fala da existência de uma ciência geral dos signos da qual a Linguística seria apenas uma parte. Para Courtine (2013), as palavras de Saussure soaram como proféticas, quando o projeto semiológico passou a servir como modelo de transferência de noções linguísticas para a Literatura, a Antropologia e a análise de imagem. Essa redescoberta da Semiologia deveu-se às mudanças científicas e tecnológicas nas comunicações humanas.
$\mathrm{Na}$ contemporaneidade, as imagens adquiriram um lugar de destaque nos estudos do discursos que empreendemos no Brasil. Segundo Courtine (2008, p. 17), "é impensável que pretendamos ainda hoje separar as palavras das imagens - imagens fixas e imagens em movimento - e que não consagremos ao funcionamento das imagens e à sua relação com o discurso a mesma atenção que dispensamos aos enunciados verbais".

Para analisar as imagens, um noção muito produtiva é a de intericonicidade, desenvolvida por Courtine e mobilizada no Brasil por Milanez (2006). A intericonicidade coloca em relação imagens externas, internas, de lembranças, da rememorização, das impressões visuais que o indivíduo guarda. Toda imagem faz ecoar imagens vistas ou imaginadas, as quais são inscritas em uma série, que deve ser reconstituída a partir dos rastros das imagens de nossa cultura.

Para Gregolin, (2007), a análise do texto não-verbal atrelado ao texto verbal abre perspectivas de estudos profícuos em $\mathrm{AD}$, visto que estamos vivenciando um momento em que a sociedade se mostra cada vez mais midiática. Por isso, conforme a autora, "os campos da $\mathrm{AD}$ e dos estudos da mídia podem estabelecer um diálogo extremamente rico, a fim de entender o papel dos discursos na produção das identidades sociais" (GREGOLIN, 2007, p. 13).

Por entendermos que o enunciado não se restringe ao nível verbal, em nossas análises, o conjunto de imagens seguidas de mensagens de advertência dos riscos do tabagismo à saúde será considerado como um enunciado, concebido como "uma função que cruza um domínio de estruturas e de unidades possíveis e que faz com que apareçam, com conteúdos concretos, no tempo e no espaço" (FOUCAULT, 2008, p. 98). O enunciado, considerado a unidade básica de análise para a $\mathrm{AD}$, mantém estreita relação com um sujeito, está presente em um campo associado e possui uma existência material.

Esse sujeito não necessariamente corresponde ao sujeito gramatical de primeira pessoa, pois ele não pode ser encontrado no sintagma linguístico e mesmo os enunciados que não possuem primeira pessoa apresentam um sujeito. Esse sujeito é uma função determinada e não coincidente consigo mesmo de um enunciado a outro, na medida em que é uma função vazia, podendo ser assumi- 
da por diferentes indivíduos, e um mesmo indivíduo ocupa diferentes posições em uma série de enunciados. Esse lugar sofre transformações e deslocamentos ao longo das diferentes épocas e possibilita verificar como um sujeito assume diferentes posições em uma série enunciativa.

Analisaremos os enunciados sobre o combate ao tabagismo em embalagens de cigarro para mostrar seu funcionamento na história e sua inserção em numa rede de formulações, que nos permitirá observar as diversas posições-sujeito construídas no discurso para o sujeito fumante, além das condições de exercício da função enunciativa a partir da visão das instâncias de poder governamental sobre o tabagismo. É a existência material desses enunciados que nos possibilita tomá-los como objeto de análise, pois trabalhamos com enunciados efetivamente realizados, e não com abstrações.

Concebemos o corpo como um objeto historicamente construído por meio do discurso. Esse objeto de estudo é "uma invenção teórica recente" (COURTINE, 2013, p. 12), datada do século XX. Para Foucault, o corpo, ao longo de seus estudos sobre a genealogia do poder, a ética e estética de si, bem como nas discussões sobre a realidade biopolítica do corpo, situa-se em um terreno de microlutas, constituindo-se um lugar perpassado por relações de poder-saber, sujeito à normatização e à resistência do sujeito.

Para Milanez (2009), o corpo que se investiga como invólucro discursivo não é o das práticas diárias, que fala, trabalha, vive, pratica esporte, deita no sofá, anda, come, dorme ou lê. Nem tampouco o corpo com suas funções biológicas. É preciso focalizar a existência material desse objeto por meio das representações com as quais o identificamos, assim como a sua existência histórica, o lugar e data em que ele aparece. Assim, diz Milanez (2009, p. 215), pode-se considerar o corpo "não somente como uma simples prática corporal e objetivante, mas como prática discursiva", no sentido foucaultiano do termo.

Para Ferreira (2013, p. 78), "trata-se do corpo que olha e que se expõe ao olhar do outro. O corpo intangível e o corpo que se deixa manipular. O corpo como lugar do visível e do invisível”. Pensar o corpo como objeto discursivo é pensá-lo como "não empírico, não biológico, não orgânico" (idem).
Portanto, o corpo do sujeito fumante, enquanto objeto discursivo, não é um dado empírico, mas está imerso em relações de saber/poder, observadas em práticas discursivas e nos processos de resistência.

\section{Biopolítica e biopoder: a governamentalidade do sujeito fumante}

Foucault (1999) diz que por muito tempo o poder soberano dispunha sobre a vida e a morte dos súditos. Para esse autor, "o direito que é formulado como de vida e morte é, de fato, o direito de causar a morte ou de deixar viver" (op. cit., p. 128 grifos do autor). Na Época Clássica houve transformações nesse poder, fazendo aparecer outro, que visava gerir a vida; a morte era seu reverso, um limite, um ponto privado da existência. Em uma sociedade como essa, só é legítima a morte daqueles que se tornam um perigo biológico para os outros.

Foucault (1999) situa no século XVIII o desenvolvimento dessa nova forma de poder, que se exerce através de dois polos interligados por um feixe de relações. O primeiro, diz ele,

centrou-se no corpo como máquina: no seu adestramento, na ampliação de suas aptidões, na extorsão de suas forças, no crescimento paralelo de sua utilidade e docilidade, na sua integração em sistemas de controle eficazes e econômicos - tudo isso assegurado por procedimentos de poder que caracterizam as disciplinas: anátomo-política do corpo humano. (FOUCAULT, 1999, p. 31 grifos do autor)

Já o segundo, formado na metade do século XVIII,

centrou-se no corpo-espécie, no corpo transpassado pela mecânica do ser vivo e como suporte de processos biológicos: a proliferação, os nascimentos e a mortalidade, o nível de saúde, a duração da vida, a longevidade, com todas as condições que podem fazê-la variar; tais processos são assumidos mediante toda uma série de intervenções e controles reguladores: uma bio-politica da população. (FOUCAULT, 1999, p. 31 grifos do autor) 
Assim, o poder sobre a vida se organiza em torno das disciplinas do corpo e das regulações da população. São duas séries que se articulam: uma disciplinar, que visa ao corpo individual, e outra regulamentar, que se exerce sobre a população, entre as quais, afirma Foucault (2005a), circula a norma.

Vivemos em uma sociedade de normalização em que a Medicina, por exemplo, é um saber-poder, uma técnica de intervenção que tem função normalizadora. Seu poder disciplinar sobre o corpo orgânico e biológico tem efeito regulamentar sobre a população.

Com essa nova forma de poder desenvolvem-se técnicas diversas de gestão e controle das populações, como as observações econômicas, dos problemas de natalidade, longevidade, saúde pública, habitação e migração. Abre-se, diz Foucault (1999, p. 132 grifos do autor), "a era do 'bio-poder", em que o homem se torna objeto do poder, integrando os fenômenos próprios à vida humana ao campo das técnicas políticas. Com isso, proliferaram tecnologias que investem sobre o corpo, a saúde, as maneiras de se alimentar e de morar, as condições de vida, etc.

A disciplina do corpo e a regulação da população dão lugar a vigilâncias, controles, ordenações, exames médicos ou psicológicos, micropoderes sobre o corpo e a medidas maciças, estimativas estatísticas, intervenções que visam ao bem-estar de toda a população.

Para Foucault (1999), estamos vivendo em uma biopolítica da espécie humana, marcada pela estatização do biológico, fenômeno que se intensificou a partir do século XIX e se ocupa "de um conjunto de processos como a proporção dos nascimentos e dos óbitos, a taxa de produção, a fecundidade de uma população, etc." (FOUCAULT, 2005a, p. 289-290). Nesse momento, devem-se tratar as doenças, pois subtraem a força e diminuem o tempo de trabalho, causando custos na economia, porque necessitam de tratamento.

Com a biopolítica, introduz-se uma Medicina que terá como função a higiene pública, através de campanhas de aprendizado e medicação da população. O biopoder objetiva aumentar a vida, controlar acidentes, eventualidades, deficiências e a própria morte, que só aparece em estatísticas, pois passou a ser um motivo de vergonha e deve ser deixada de lado pelo poder, que vai se esforçar para manter vivo até mesmo aquele que já deveria estar morto.

A passagem de uma arte de governar, da soberania, para uma ciência política, dominada pelas técnicas de governo em torno da população, no século XVIII, não implica a passagem de uma sociedade de soberania para uma disciplinar e depois para uma sociedade de governo, mas de um triângulo em que a população é o alvo principal e os mecanismos essenciais são os dispositivos de segurança. Vivemos, desde o século XVIII, na era da governamentalidade, entendida como:

1) o conjunto constituído pelas instituições, procedimentos, análises e reflexões, cálculos e táticas que permitem exercer esta forma bastante específica e complexa de poder, que tem por alvo a população, por forma principal de saber a economia política e por instrumentos técnicos essenciais os dispositivos de segurança.

2) a tendência que em todo Ocidente conduziu incessantemente, durante muito tempo, à preeminência deste tipo de poder, que se pode chamar de governo, sobre todos os outros - soberania, disciplina etc. - e levou ao desenvolvimento de uma série de aparelhos específicos de governo e de um conjunto de saberes.

3) o resultado do processo através do qual o Estado de justiça da Idade Média, que se tornou nos séculos XV e XVI Estado administrativo, foi pouco a pouco governamentalizado. (FOUCAULT, 2013a, p. 429)

É importante destacar que, para Foucault (2013a), governar é uma prática múltipla, que pode ser exercida por muita gente, como o pai de família, o pedagogo e o professor e o governo do Estado. Este último é uma modalidade entre tantas outras formas de governo, no interior da qual as demais estão contidas. Essas modalidades inserem-se em três tipos de governo, cada um se referindo a uma forma de ciência ou de reflexão: governo de si mesmo (moral), da família (economia) e do Estado (política), e há uma continuidade entre elas, pois aquele que quer ser um bom governante para o Estado, primeiro, deve saber se governar e ser um bom chefe de família, do mesmo modo que o Estado bem governado é aquele em que os pais de família sabem governar sua família e os indivíduos se comportam como devem. 
Assim, governar significa dispor as coisas de um modo correto para conduzi-las a um objetivo adequado a cada coisa a governar: fazer com que se produza mais riqueza, com que se forneçam às pessoas, meios suficientes de subsistência. O que se entende por "dispor as coisas", diz o autor, é "utilizar mais táticas do que leis, ou utilizar ao máximo as leis como táticas" (FOUCAULT, 2013a, p. 418). A gestão populacional tem como objetivo final aumentar a saúde, a riqueza e a duração da vida. Para atingir isso, o governo deve usar como instrumentos:

Campanhas, através das quais se age diretamente sobre a população, e técnicas que vão agir indiretamente sobre ela e que permitirão aumentar, sem que as pessoas se deem conta, a taxa de natalidade, ou dirigir para uma determinada região ou para uma determinada atividade os fluxos da população. (FOUCAULT, 2013a, p. 425)

Para Hardt e Negri (2001, p. 42, grifos dos autores), na sociedade de controle, que se desenvolve nos limites da modernidade e se abre para a pós-modernidade, os "mecanismos de comando se tornam cada vez mais 'democráticos', cada vez mais imanentes, ao campo social, distribuídos por corpos e cérebros dos cidadãos".

O poder é exercido mediante máquinas que organizam diretamente o cérebro, (em sistemas de comunicação, redes de informação, etc.) e os corpos (em sistemas de bem-estar, atividade monitorada, etc.), intensificando os aparelhos de normalização de disciplinaridade, que controlam nossas práticas diárias.

O biopoder "regula a vida social por dentro, acompanhando-a, interpretando-a, absorvendo-a e a articulando" (HARDT e NEGRI, 2001, p. 43). Para isso, todos os indivíduos devem abraçá-lo por sua própria vontade como função vital. O que está em jogo é a produção e a reprodução da vida. Quando o poder se torna inteiramente biopolítico, todo o corpo social é abraçado pela máquina do poder e desenvolvido em sua virtualidade. A sociedade reage como um só corpo. O poder se estende pelas profundezas da consciência e dos corpos da população.

A partir dessas discussões, consideramos que os enunciados antitabagistas que compõem nosso corpus inserem-se no quadro de uma estratégia biopolítica (FOUCAULT, 1999) por meio da qual se promove a gestão da vida da população, objetivando diminuir os riscos de acometimento por doenças para as quais o tabaco é um fator de risco. A governamentalidade (FOUCAULT, 2013a) do sujeito fumante ocorre mediante a construção de um "conjunto decididamente heterogêneo que engloba discursos, instituições, organizações arquitetônicas, decisões regulamentares, leis, medidas administrativas, enunciados científicos, proposições filosóficas, morais, filantrópicas" (FOUCAULT, 2013b, p. 364), ao qual Foucault (2013b) denomina de dispositivo.

Estamos chamando metodologicamente de dispositivo de combate ao tabagismoo conjunto constituído de discursos científicos que alçaram o tabagismo à condição de doença, instituições de controle sanitário, como a Agência Nacional de Vigilância Sanitária (ANVISA), o Ministério da Saúde, e o Instituto Nacional do Câncer (INCA), leis de regulamentação do consumo de cigarro, como a Lei Antifumo (Lei 12.546/2011), etc. "Em suma, o dito e o não dito são os elementos do dispositivo. O dispositivo é a rede que se pode estabelecer entre estes elementos" (FOUCAULT, 2013b, p. 364).

Gostaríamos de caracterizar a análise enunciativa proposta por Foucault (2008), para explicarmos como reunimos os enunciados em torno de um mesmo tema, orientando-nos pelas regularidades discursivas entre eles. Essa análise diz que, para encontrarmos as regularidades do enunciado, precisamos descrever o funcionamento de quatro elementos que caracterizam a formação discursiva e dão unidade ao discurso. Interessa-nos aqui particularmente a regra de formação dos objetos, que diz respeito à existência de um determinado objeto no discurso. Para encontrá-la, é preciso delimitar as suas superfícies de emergência; descrever as instâncias de delimitação, ou seja, as esferas sociais autorizadas a falar do objeto, e por fim analisar as grades de especificação, os sistemas pelos quais um mesmo objeto é separado, reagrupado e classificado nas diferentes áreas que falam dele.

Estamos considerando a embalagem de cigarro como a superfície de emergência de nosso objeto, na qual há diferentes grades de especificação do tabagismo, que são as doenças para as quais ele é considerado um fator 
de risco. As instâncias de delimitação são a Medicina e os órgãos governamentais que regulamentam o consumo de cigarro e promovem o combate ao tabagismo, tais como a ANVISA, o INCA e a Lei 2.546/2011.

Assim, a partir da noção de regularidade, reunimos os enunciados em torno da grade de especificação de doenças cardíacas e vasculares para as quais o tabagismo é um fator de risco. Mesmo que não apareça na superfície discursiva, o discurso sobre o combate ao tabagismo está imbricado no discurso sobre a morte, como pode ser visto na figura 1 , que data de 2008 e cuja escolha temática (FOUCAULT, 2008) localizada na parte superior é "perigo".

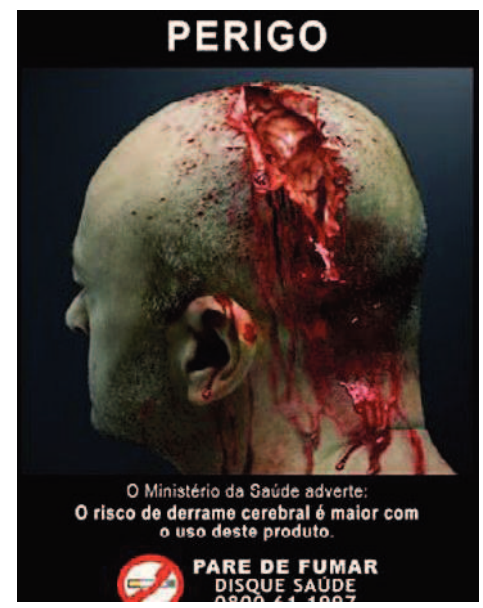

Figura 1: Perigo. Fonte: INCA, 2008

Para conduzir nossa análise, faremos um batimento, na esteira de Pêcheux (2006), entre descrição e interpretação. Assim, nesse enunciado tem-se a imagem de uma cabeça com uma perfuração, da qual escorre sangue, espalhando-se pelo coro cabeludo, orelha e pescoço. A parte não-verbal desse enunciado foi produzida com recursos digitais que modificam a imagem da cabeça e fazem com que ela pareça estar dilacerada. Portanto, não há na imagem um retrato real da doença vascular cerebral, e sim uma didatização do risco de derrame cerebral, pois sabemos que não é dessa forma que essa doença se manifesta nas pessoas, com sangue jorrando pela superfície externa do corpo enquanto o sujeito ainda fica de pé.

A parte verbal também deixa entrever o caráter didático desse enunciado ao empregar a lexia "derrame" no lugar de "acidente vascular cerebral", pois a forma mais coloquial torna o alerta mais acessível aos sujeitos. Além disso, destacamos da mensagem de alerta que diz que o risco de derrame cerebral aumenta com o uso do cigarro, que esse produto é apenas um agravante para o derrame cerebral, e não seu causador exclusivo.

A nosso ver, o sangue que escorre pelo corpo do sujeito é um elemento dual, pois pode simbolizar a permanência da vida, mas nesse enunciado o seu derramamento está servindo para representar o acometimento pelo derrame cerebral, que implica em a possibilidade de morte. Ao alertar para esse risco, alerta-se também para a possibilidade de morte súbita. Em nossa sociedade, em que o biopoder estatizou o biológico, conforme Foucault (1999), a morte é parte de um ritual que deve ser escondido, e por isso devem-se tomar os devidos cuidados com o corpo como forma de resistir e negar a morte, buscar prazeres como forma de aproveitar a finitude da vida. Para viver bem e afastar a possibilidade de morte súbita, é sugerido ao sujeito abandonar o cigarro, que potencializa esse risco.

Esses discursos controlam a existência dos sujeitos, de modo a evitar as degradações biológicas do seu corpo. O sujeito também deve governar a si, por meio do controle de suas práticas, seus hábitos, porque eles envolvem não só sua vida, mas a vida de toda a população. Se há muitos indivíduos morrendo, é sinal que o governo não está cuidando de seus governados e nem conseguindo fazê-los cuidar de si mesmos. Por isso esse tipo de acidente deve ser controlado.

O sujeito é desidentificado do seu rosto, aparecendo apenas de perfil, pois sua cabeça dilacerada é o ponto para o qual o olhar deve ser direcionado. Nesse enunciado, não importa quem seja o indivíduo que fuma. Interessa o sujeito, compreendido como uma função enunciativa (FOUCAULT, 2008a), um efeito de discurso. Essa função pode ser exercida por qualquer indivíduo, desde que obedeça a um determinado número de regras, que o constituem como sujeito da prática de fumar.

Diferentemente do enunciado anterior, no enunciado 2, a busca pelo choque recorre a um efeito de realidade, que chega a uma dimensão biográfica. Utiliza-se aqui a estratégia da confissão (FOUCAULT, 1999) de um sujeito que teve a perna amputada em decorrência de doença vascular, conforme especificado na parte 
verbal do enunciado, como forma de incentivar o abandono do cigarro.
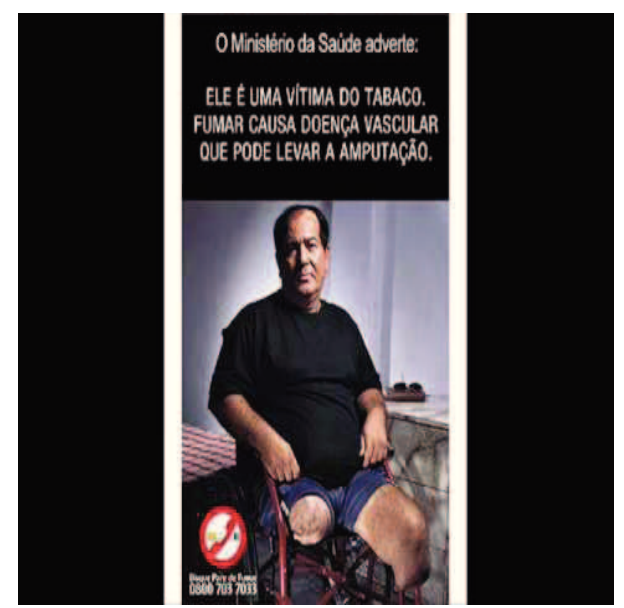

Figura 2: Ele é uma vítima do tabaco. Fumar causa doença vascular que pode levar à amputação. Fonte: INCA, 2003

O sujeito mostrado nesse enunciado é um apresentador chamado José Carlos Carneiro, que cedeu sua imagem para a propaganda como forma de alertar a sociedade para os malefícios do tabaco. Na época (2003), esse acontecimento foi amplamente divulgado na mídia, mas após alguns anos ele se arrependeu da atitude e entrou com uma ação judicial para retirar sua imagem das embalagens de cigarros que iriam para o mercado.

Outra diferença em relação à imagem anterior é que esta aqui não possui alteração digital. Mesmo assim, foi produzida de modo a causar choque, pelo enquadramento, visando criar um efeito de verdade, pela posição do apresentador, sério, sentado na cadeira de rodas, e pela camisa de cor preta usada por ele, que, ao mesmo tempo em que ajuda a não direcionar o olhar para ela por não possuir estampa nem outra coisa que prende o olhar, remete ao luto, pelo menos em nossa cultura, fazendo acionar o discurso da morte.

As duas pernas do jornalista, amputadas em proporções irregulares, agenciam para esse sujeito um corpo "monstruoso e anormal", no sentido foucaultiano, ou seja, um corpo que foge à norma e a põe em ameaça. Para Foucault (2001), de um lado, a norma pode ser "entendida como regra de conduta, como lei informal, como princípio de conformidade; à norma se opõe à irregularidade, à desordem, ao bizarro, à excentricidade, aos afastamentos, à desnivelação" (2001, p.204), e, por outro lado, como "regularidade funcional, como princípio de funcionamento adaptado e ajustado; eis a 'norma' em que se oporá o patológico, o mórbido, o desalinhado, o sem função" (idem, grifos do autor).

O fumante emerge como um corpo deformado e com dimensões dissimétricas. Esse corpo monstruoso quebra os paradigmas da normalização e nos coloca diante de órgãos que estão putrefatos. No saber biológico, o corpo do homem é um sistema feito de órgãos interligados, cuja função é, após o nascimento, crescer, reproduzir-se e morrer, mas a morte para o fumante resulta da não observância às regras de conduta construídas socialmente, uma punição, um efeito da disciplina. Esse sujeito está em confronto com os poderes que regulam suas práticas, e sua morte tem ação moralizante, incidindo diretamente em seu corpo, que agora não tem nenhuma utilidade para a sociedade.

Destacamos também da sequência verbal: "Ele é uma vítima do tabaco. Fumar causa doença vascular que pode levar à amputação", que a ideia de vítima sempre deixa implícito um vilão, que nesse caso é o cigarro, e não o sujeito fumante, como no caso dos enunciados que alertam para o risco do tabagismo passivo.

Ainda tratando da grade de especificação (FOUCAULT, 2008) de doenças vasculares, a figura 3 mostra um pé com uma gangrena, uma consequência visível no corpo da obstrução das artérias pelo consumo excessivo de cigarro, o que dificulta a circulação sanguínea.

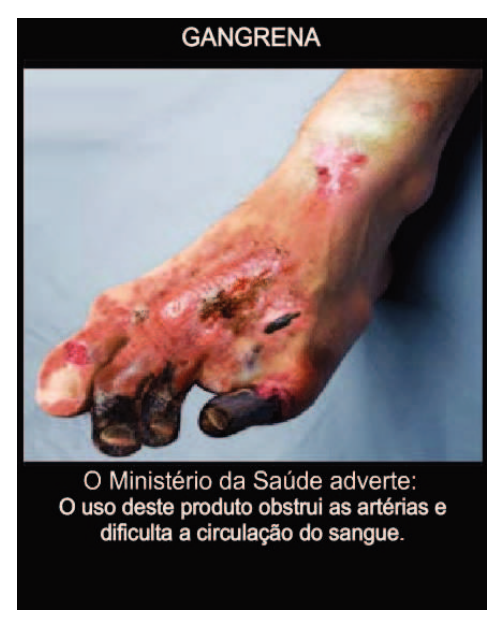

Figura 3: Gangrena. Fonte: INCA, 2008.

O grupo de imagens produzidas em 2008, da qual essa faz parte, foi modificado digitalmente. Nesse enun- 
ciado, as feridas avermelhadas no pé e nos dedos, a ausência de um dos dedos e os três dedos escurecidos, como se houvesse um acúmulo de cinzas neles, sãos o traços que compõem a deformidade do corpo do sujeito fumante. Neste caso, há um apagamento total de todo o corpo do sujeito, ficando somente o pé necrosado visível, como se sua identidade fosse reduzida a um corpo doente.

Chamamos a atenção para a sequência: "O uso deste produto obstrui as artérias e dificulta a circulação do sangue", na qual não há uma relativização sobre até que ponto esses males podem ser desencadeados, pois se tem a impressão que no simples ato de consumir o produto já se é acometido pelos males descritos no enunciado.

Os danos do tabagismo afetam diversas partes do corpo, da superfície visível, aos órgãos internos. Assim, na figura 4, adentramos ao corpo do sujeito fumante, para visualizar seu peitoral, que está aberto e ladeado por aparelhos cirúrgicos, como se um procedimento médico estivesse sendo feito no coração, o que evoca a presença do ambiente hospitalar em que um paciente estaria fazendo uma cirurgia no coração, o que é reforçado pela mensagem de alerta.

O coração é metaforicamente tratado como um cinzeiro, sobre o qual estão depositados restos de cigarro numa quantidade exorbitante.

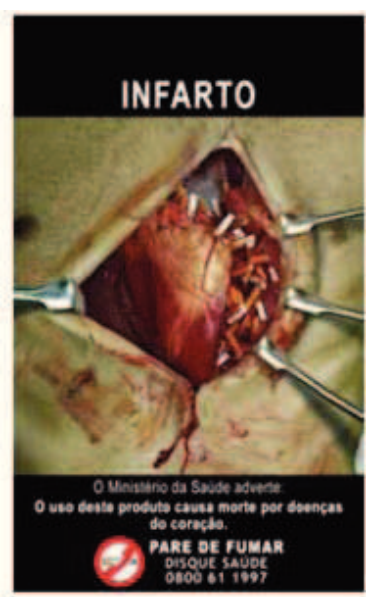

Figura 4: Infarto. Fonte: INCA, 2008.

Esse enunciado também faz parte do grupo de imagens produzidas em 2008 e possui um caráter altamente simbólico e irreal, chegando a ser utópico. O que ele mostra é uma idealização do corpo do sujeito fumante, pois sabemos, com o discurso clínico que constrói essa verdade, que os restos do cigarro não se depositam no coração. São as substâncias tóxicas que ele possui que circulam pelos órgãos internos.

Além disso, a sequência verbal: "O uso deste produto causa morte por doença do coração" também não relativiza até que ponto o uso do cigarro desencadeia a morte, dando a impressão de que o simples ato de consumir o produto provoca a morte do fumante. Destacamos também a presença do discurso da morte como um risco iminente.

No discurso antitabagista que analisamos, o corpo do sujeito fumante é discursivizado como deformado, monstruoso, cujos órgãos estão putrefatos, sempre na iminência de morrer, pois ele é um sujeito que não obedece às regras de conduta construídas socialmente. Seu adoecimento e morte são punições por confrontar os poderes que visam regular suas práticas, controlar seu corpo.

Essas imagens buscam provocar medo e repulsa. Para Courtine (2008), as preocupações mais intensas e persistentes da vida são os medos. Temos, na contemporaneidade, uma infinidade deles, alguns desencadeados por acontecimentos, sustentados por crises, mas existe também "uma produção, uma gestão, uma encenação e uma difusão do pavor" (p. 18) por meio de palavras, narrativas e imagens que circulam em aparelhos de informação, e promovem o governo pelo medo. Diante de tantos medos, é provável que "não haja território mais imprevisível e movediço do que o medo da morte" (SANTOS, 2014, p. 122), já que a certeza da finitude da vida alia-se à incerteza de quando chegará esse fim, causando desequilíbrio e desespero diante da possibilidade de se estar contribuindo para que o perecimento seja iminente.

\section{O cuidado de si como prática de objetivação/ subjetivação do sujeito fumante}

Neste tópico, nos propomos a pensar a constituição do sujeito fumante a partir da relação do combate ao tabagismo com os riscos de doenças cancerígenas, que cruza o domínio médico e estético, inserindo o sujeito entre o biopoder e o cuidado de si, pois a margem para 
resistir ao poder normalizador é mínima, já que há uma positividade nessa forma de poder, fazendo com que o sujeito se deixe governar. Assim, a governamentalidade põe em tensão modos de objetivação e de subjetivação. Por isso, interessa-nos caracterizar as relações que o sujeito fumante é convocado a desenvolver de si para consigo e como essas relações se inserem naquilo que Foucault (2005b, p. 49) denomina de "cultura de si", ou seja, a "intensidade das relações consigo, isto é, das formas nas quais se é chamado a se tomar a si próprio como objeto e campo de ação para transformar-se, corrigirse, purificar-se, e prover a própria salvação".

Foucault estuda os modos de subjetivação do ser humano, que "diz respeito às práticas, às técnicas, por meio das quais o sujeito faz a experiência de si mesmo em um jogo de 'verdade'. Esses processos de subjetivação são diferentes e diversos nas diferentes épocas" (GREGOLIN, 2008b, p. 94, grifos da autora). Por essa prática, o ser humano se transforma em sujeito de si para si.

Essa cultura de si caracteriza-se, segundo Foucault (2005b, p. 49, grifos do autor), "pelo princípio segundo o qual é preciso 'ter cuidado consigo'; é esse princípio do cuidado de si que fundamenta a sua necessidade". Portanto, o que legitima essa cultura de si é a ideia de que se deve ocupar-se consigo mesmo. "Existem os cuidados com o corpo, os regimes de saúde, os exercícios físicos sem excesso, a satisfação, tão medida quanto possível, das necessidades" (FOUCAULT, 2005b, p. 56).

Foucault (2005b, p. 59) observa que há uma tradição, que remonta à cultura grega, na qual "o cuidado de si está em correlação estrita com o pensamento e a prática médica". Essa correlação ampliou-se, e, na atualidade, a Medicina apresenta-se como um saber normalizador de práticas higienistas de cuidados com o corpo.

Segundo Foucault, a racionalidade para o governo do outro é a mesma que a racionalidade do governo de si próprio. Por isso, ao mesmo tempo em que discutiremos a relação do sujeito com a ética e sua constituição por meio de práticas de si, pensaremos as formas de governo dos outros.

$\mathrm{O}$ ato de fumar é uma prática discursiva (FOUCAULT, 2008) que aparece em época e lugar específicos e se desloca na história. No interior dessa prática, o sujeito fumante é especificado por saberes, que o ligam a uma identidade ao definirem as condições de exercício da função enunciativa (op. cit.), e também se deslocam discursos que provocam mudança na sociedade e na própria posição que esse sujeito passa a ocupar. Assim, com a emergência do discurso de combate ao tabagismo, essa prática deslocou a posição que o sujeito fumante ocupava na sociedade. Nas embalagens de cigarro um conjunto de escolhas temáticas (op. cit.) é agenciado, fazendo com que o ato de fumar seja atravessado por representações discursivas que instauram um lugar para esse sujeito e mostram a forma como a sociedade se relaciona com ele.

$\mathrm{O}$ enunciado que mostramos a seguir na figura 5 tem como escolha temática o horror.

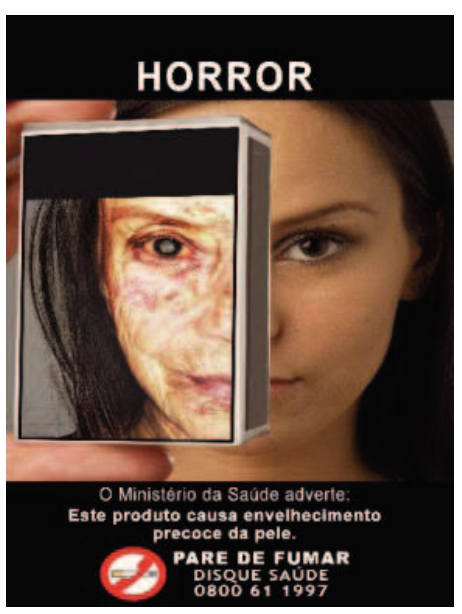

Figura 5: Horror. Fonte: INCA, 2008.

Segundo o discurso médico que perpassa o combate ao tabagismo, as substâncias presentes no cigarro são consideradas um fator que potencializa o desenvolvimento de cânceres que podem acometer o sujeito fumante. Nesse enunciado, a embalagem de cigarro, enquanto superfície de emergência (FOUCAULT, 2008), mobiliza o discurso clínico como instância de delimitação (op. cit.) autorizada a falar de tal objeto de discurso, ao mesmo tempo em que propõe formas de o sujeito cuidar do corpo para evitar a degradação física.

$\mathrm{Na}$ superfície discursiva, podem-se vislumbrar as grades de especificação (op. cit.) desse discurso, que mostram o envelhecimento como um horror, a partir da sequência: "O Ministério da Saúde adverte: este produto causa envelhecimento precoce", na qual o discurso 
da saúde é permeado por uma preocupação estética. O contraste entre o corpo velho e o novo ocorre por meio de uma referência ao espelho, como se o consumo de cigarro indicasse um caminho para o envelhecimento como algo negativo, visto pelo espelho, metaforizado na própria embalagem desse produto.

Em nossa época, em que há tantos recursos estéticos para prolongar a juventude, o envelhecimento precoce deve ser evitado, e nesse caso, o tabagismo é um fator que o potencializa.

O envelhecimento cronológico é um processo que não pode ser evitado e por isso representa uma ameaça para um corpo jovem, o que o torna indesejável. Percebendo essa aversão que o envelhecimento traz, a mídia "sugere formas de controle dos efeitos negativos do processo de envelhecimento" (MONTEIRO, 2014, p. 16). Desse modo, o envelhecimento precoce se torna sinônimo de falta de cuidado de si (FOUCAULT, 2005b). É preciso, então, cuidar da aparência, evitar o que horroriza o corpo.

Quanto à escolha temática, localizada na parte superior do enunciado, Milanez (2011, p. 30) destaca que a possibilidade de emergência da imagem do horror em nossa época encontra respaldo "nas necessidades, anseios e temores do sujeito contemporâneo", sendo o horror "um lugar de produção de discurso do qual fazem parte uma coleção de figuras distintas baseadas em tabus dos quais estamos proibidos de falar". Assim, para esse autor, os sujeitos lançam um olhar para o mundo a partir de técnicas e regras ligadas ao corpo no plano biológico, cuja degradação conduz ao pavor.

A produção desse enunciado pelo poder governamental com o intuito de combater o tabagismo recorre ao discurso estético, ao mesmo tempo em que constrói o sujeito fumante como um objeto biológico, um corpo degradável, que pode sofrer os horrores do envelhecimento. Mas esse discurso só tem respaldo porque leva em conta que, na sociedade contemporânea, impera um desejo de longevidade.

A partir da figura 6 continuaremos a discutir a relação do tabagismo com os riscos de desenvolvimento de cânceres. Esta imagem data de 2003 e pode-se observar que sua estruturação difere das imagens produzidas em 2008. As mensagens de alerta se localizam na parte superior e não há um sintagma isolado servindo de especificação do campo a que o alerta se refere. É a sequência "O Ministério da Saúde adverte: fumar causa câncer de boca e perda dos dentes" que dará as grades de especificação do alerta.

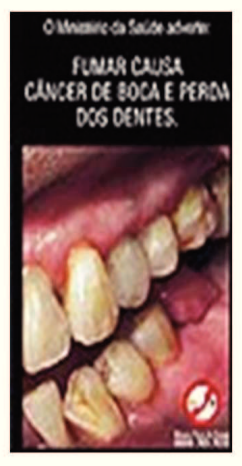

Figura 6: Fumar causa câncer de boca e perda dos dentes. Fonte: INCA, 2003.

Mesmo tendo circulado em épocas distintas, há, como se vê, uma regularidade entre esse enunciado e o anterior, pois mais uma vez o domínio do discurso médico se cruza com o discurso estético, visto que o cuidado com a saúde bucal é uma questão de saúde e de estética. Os discursos sociais que diariamente circulam em propagandas de creme dental e outros produtos de higiene bucal dizem que o sujeito deve ter um sorriso branco, dentes bem alinhados, além de uma saúde bucal em ordem.

Nas grades de especificação desse enunciado, a campanha chama atenção para a possibilidade de o fumante desenvolver câncer de boca e vir a perder os dentes em decorrência do consumo de cigarro. Esse enunciado possui um investimento forte no choque pelo efeito de realidade que possui ao mostrar uma boca em que alguns dentes estão estragados, amarelados e uns foram perdidos.

Nesse enunciado, o sujeito é governado pelo outro e ao mesmo tempo é convocado a governar a si mesmo (FOUCAULT, 2013a), pois suas práticas higienistas também ajudam a prevenir esses cânceres, para os quais o cigarro é apenas um agravo. Essas práticas de higiene possibilitam pensar "práticas de si que falam de 
sujeitos controlados, sujeitos que governam a si e sujeitos que cuidam de si e dos outros" (MILANEZ, 2009, p. 216). O corpo no interior de práticas higieneizantes aparece como "suporte primeiro na recepção e produção dos ecos de nossa cultura" (op. cit.), pois elas são historicamente produzidas por meio de conhecimentos seculares. Segundo o discurso clínico, os cuidados com a saúde bucal devem ser diários, incluindo consulta periódica e regular a um dentista, escovação dos dentes várias vezes ao dia, etc.

Milanez (2009, p. 219) considera que, ao aceitarmos as práticas de higiene do corpo, estabelecidas por disciplinas de conveniência social, aplicadas a instituições como a mídia e a clínica, estamos nos vinculando a uma disciplina normalizadora. Começamos também a nos posicionar como sujeito que se ocupa consigo mesmo na relação interindividual com as trocas diárias. Assim, a higiene bucal constitui uma arte da existência (FOUCAULT, 2005b) de nós mesmos, o que implica ter cuidados conosco, aplicar-nos a nós próprios.

Ainda tratando de cânceres, mas de outro tipo, a figura 7, cuja produção data de 2003 , trata da possibilidade de desenvolvimento de câncer de laringe, como pode ser visto no enunciado: "O Ministério da Saúde adverte: fumar causa câncer de laringe", que possui os mesmos padrões que assinalamos para a mensagem anterior, já que são do mesmo grupo em termos de temporalidade da produção.

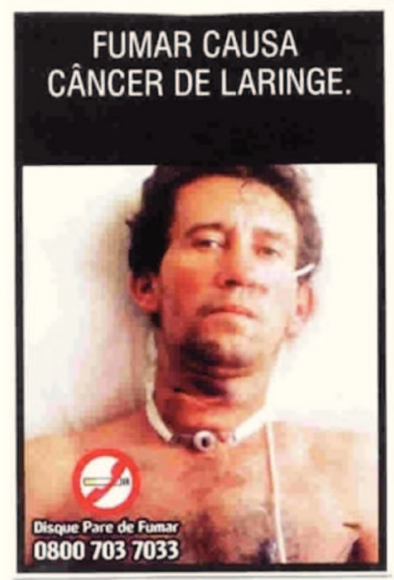

Figura 7: Fumar causa câncer de laringe. Fonte: INCA, 2003.

Recorrendo ao medo, a imagem mostra um homem, no ambiente hospitalar, com o corpo envolto por tubos e aparelhos cirúrgicos. A expressão facial de tristeza e o olhar do sujeito ajudam a compor a imagem do fumante nesse discurso, como um doente que está sempre na iminência da morte. Há uma especificação minuciosa dos riscos do tabagismo, que não se atém só à superfície visível do corpo.

A sequência que demos à análise desses enunciados dá a impressão que o corpo desse sujeito vai se deteriorando em um percurso que se inicia na pele, passa pela boca, e chega aos órgãos respiratórios e circulatórios, como se verá mais adiante na imagem que alerta para a possibilidade de desenvolvimento de câncer de pulmão.

A imagem de um sujeito que está perecendo de um mal decorrente de sua própria atitude dá um tom confessional (FOUCAULT, 1999) ao enunciado, mesmo sabendo que se trata de um modelo que posou para as lentes de uma câmera e que, provavelmente, não fuma. Além disso, há um efeito de lição de moral perpassando esse enunciado, como um exemplo que deve ser guardado, mas não seguido.

$\mathrm{Na}$ figura 8, que se segue, é acionado o discurso da morte. Na parte verbal, é especificado o domínio a que se direciona o alerta, enquanto que na parte nãoverbal o rosto do sujeito é apagado, deixando à mostra somente o peitoral costurado até a clavícula e aberto na parte do abdômen. A mensagem de alerta chama atenção para os riscos de desenvolver câncer de pulmão e enfisema, e como consequência final, a morte.

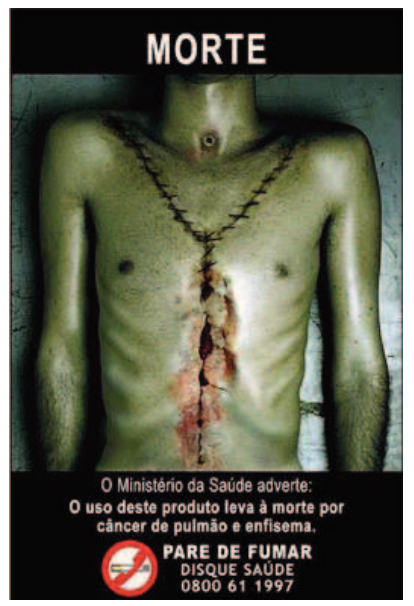

Figura 8: Morte. Fonte: INCA, 2008

É interessante perceber que aqui aparece a imagem de um corpo masculino sendo relacionado a 
esses riscos decorrentes do tabagismo e ainda assim há uma dimensão estética nesse discurso, situada no abdômen, símbolo de vaidade masculina na nossa época. Além disso, o apagamento do rosto do sujeito nessa imagem é muito significativo, pois o despoja de algo que é o seu principal identificador, tornando-o anônimo. Para Milanez (2009), o apagamento da identidade do rosto desidentifica o sujeito de suas paixões, desloca-o de seus lugares político-sociais, e torna-o um anônimo na multidão, dando privacidade a ele num mundo em que a visibilidade é a palavra de ordem. O autor acrescenta que o corpo tem seus limites históricos, e sua aparência pode revelar mecanismos que pertencem a um terreno biossocial.

Nas embalagens de cigarro, temos identidades construídas pelo biopoder (FOUCAULT, 1999), evocando sinais científicos que atestam o adoecimento do corpo do sujeito fumante. Do ponto de vista discursivo, o sujeito, para Foucault (2008), é um lugar vazio, uma função que pode ser ocupada por qualquer indivíduo que assuma determinado papel. $\mathrm{O}$ sujeito fumante deve confessar-se como tal para que seja o sujeito dessa identidade.

Como já assinalamos, há em nossa época um grande desejo de longevidade, que difunde a ideia de que os recursos estéticos existentes ajudam a prolongar a vida. A morte é um reverso desse desejo, um temor para a sociedade. Por isso, ela é uma constante no discurso antitabagista e as regularidades enunciativas nos possibilitam vê-la metaforizada também na figura 9, cuja grade de especificação é a toxidade das substâncias que o cigarro possui. Ela trata tanto da temática do adoecimento quanto da morte, mas aqui não se especifica um órgão ou sistema do corpo humano sobre o qual recai a suscetibilidade de acometimento por doença, nem se especifica uma doença. O foco, portanto, é sobre o produto em si e seus efeitos nocivos, como se pode ver na sequência localizada na parte inferior do enunciado.

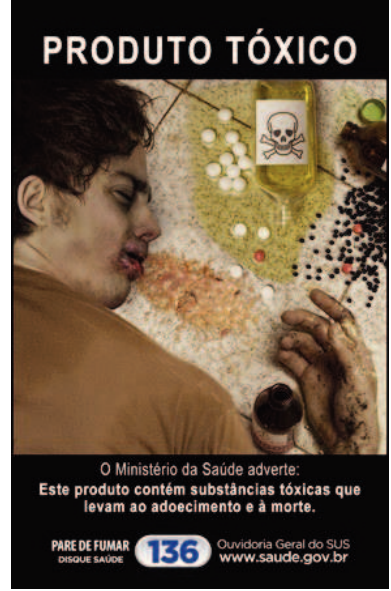

Figura 9: Produto tóxico. Fonte: INCA, 2008.

Essa imagem é artisticamente construída. Nela aparece um rapaz desmaiado, cercado de vidros de produtos tóxicos presentes no cigarro e com vômito expelido por ele misturado a esses produtos. Pelo que a mensagem de alerta diz, pode-se afirmar que ele está morto pelo consumo excessivo desse produto (overdose). Além disso, a ideia de morte é materializada no símbolo que a representa iconicamente no vidro de produtos tóxicos e venenosos. Metonimicamente, tal ícone está simbolizando o efeito desse produto venenoso no organismo humano. Diferente da figura anteriormente mostrada, que despossui o sujeito do rosto, aqui ele aparece, mas apenas de perfil, além de uma de suas mãos, que aparece suja pelos produtos que se misturam no chão.

Ainda sobre o discurso da morte presente nos enunciados das figuras 8 e 9 , voltamos a nos referir a Milanez (2009, p. 21), para quem a morte, em nossa época, é um tabu maior que o sexo e, nesse sentido, se torna

a própria realização da finitude que nós, sujei-
tos contemporâneos, denegamos tão fortemen-
te, utilizando técnicas de autocontrole veicula-
das pela clínica, desde um creme para rugas até
a cirurgia plástica estética ou mesmo a pseu-
dociência midiática nas reportagens de revistas
que reproduzem dietas e ginásticas, ensinan-
do-nos como ocupar-nos com nossos corpos.
Enfim, um mecanismo pedagógico sutil para
possibilitar o prolongamento de nossas vidas.

Assim, para esse autor, a ânsia pelo desejo de viver até os últimos momentos reveste a morte do gozo total por uma prática ideal de si e levanta o medo da mor- 
te, buscando evitá-la por meio de práticas de satisfação consigo próprio, como se estivéssemos vivendo sempre o nosso último dia, sem temer a morte, pois hoje é proibido morrer. A estratégia é mostrar ao sujeito que, numa época em que o biopoder (FOUCAULT, 2005a) assume a responsabilidade pela gestão da vida da sociedade, não se submeter a ele acarreta a subtração da vida, cuja responsabilidade é exclusiva do sujeito que resiste.

Desse modo, é o discurso, em seu funcionamento sob a modalidade de linguagem sincrética, que cria efeitos de identidades para o sujeito fumante, recorrendo a imagens de horror, motivado principalmente pelo monstruoso, que ameaça, provoca medo e repulsa. As diversas cenas que expõem os riscos a que o corpo do fumante está sujeito causam medo da morte e abalam o homem, pois implicam a consciência de que ele é um ser finito e incapaz de driblar a morte. Para criar o efeito de horror e de medo, as imagens são cuidadosamente trabalhadas, recorrendo ao imaginário coletivo e às narrativas populares, como os seres sem cabeça, que se tornam também sem nome, sem rosto e "sem identidade".

\section{Considerações finais}

A partir do momento em que as doenças decorridas do tabagismo se tornaram preocupações políticas, a governamentalidade se ocupou destes temas, disciplinando a população por meio de campanhas antitabagistas, como a inserção de imagens sanitárias em embalagens de cigarro, cujo objetivo final é prevenir doenças decorrentes do uso do tabaco e, consequentemente, diminuir gastos com a saúde pública. Assim, o ato de fumar deixou de ser um símbolo de status e poder e se tornou um risco à saúde do fumante. É a Medicina que produz verdades sobre a saúde e os cuidados com o corpo, dando respaldo ao controle exercido pelas instituições governamentais que normatizam os hábitos dos sujeitos.

Nos enunciados cujas grades de especificação são os riscos de acometimento por doenças cancerígenas e cardiovasculares cruzam-se o domínio médico e estético, fazendo incidir mecanismos de poder/saber sobre a população, por meio de campanhas de prevenção ao tabagismo, que se ancoram em saberes oriundos da
Medicina, a qual tem função normalizadora na vida da população. Esses enunciados são legitimados por instituições jurídicas e outros órgãos de Estado, que controlam o funcionamento do discurso antitabagista, ao mesmo tempo em que constroem discursivamente o sujeito fumante como um corpo doente e que vive na iminência da morte.

Há, portanto, um poder que gerencia a vida, indicando modos de manter o corpo segundo os padrões considerados saudáveis na contemporaneidade, em que os sujeitos anseiam por longevidade e temem a morte. Resistir a esse poder implica ser punido por doenças cardiovasculares, cânceres, envelhecimento precoce e, num caso mais extremo, pela morte, maior temor de nosso tempo, que deve ser interditado do processo de construção de nossas subjetividades. O discurso que perpassa tais enunciados leva ao cuidado do sujeito $\mathrm{fu}$ mante consigo próprio e também com o outro.

\section{Notas}

1. Todas as imagens de advertência sanitária utilizadas aqui estão disponíveis em: www. inca.gov.br/tabagis mo/publicacoes/ asiladvertenciassanitariasnosprodutosdetabaco2009b. pdf. Acesso em 23/03/2015.

2. O termo Nova História é empregado aqui em referência à história da chamada École dês Annales, em torno da revista Annales: économies, societés, civilisations, fundada em 1929 por Lucien Fevre e Marc Bloch para divulgar seus trabalhos. Na geração seguinte está associada a Fernand Braudel, que dirigiu a revista supracitada entre 1958 e 1969, junto a com Charles Morazé. Após isso, uma nova diretoria, que contava com Jacques Le Goff, a comandou.

3. Não estamos tão certos em dizer que a Semiologia Histórica é um campo teórico à parte da Linguística, pois ela mobiliza problematizações já presentes no interior dela, como as discussões de Barthes sobre o mito, em Mitologias. Preservamos aqui essa denominação por ser a forma como o autor se refere aos estudos que realizou sobre imagem.

\section{Referências}

BURKE, Peter (Org.). Abertura: a nova história, seu passado e seu futuro. In: (org). A escrita da história: novas perspectivas. Trad. Magda Lopes. São Paulo: Editora Unesp, 2011, p. 7-38. 
COURTINE, Jean-Jacques. Discursos sólidos, discursos líquidos: a mutação das discursividades contemporâneas. Trad. Carlos Piovezani. In: SARGENTINI, Vanice; GREGOLIN, Maria do Rosário (orgs.). Análise do discurso: heranças, métodos e objetos. São Carlos: Editora Claraluz, 2008, p. 11-19.

. Análise do Discurso Político: o discurso comunista endereçado aos cristãos. São Carlos: EdUFSCar, 2009.

Introdução. In: CORBIN, Alain; COURTINE, J.J; VIGARELLO, Georges. História do Corpo: as mutações do olhar: o século XX. Trad. Ephraim Ferreira Alves. $4^{\mathrm{a}}$ ed. Petrópolis: Vozes, 2011a, p. 7-12.

Decifrar o corpo: pensar com Foucault. Trad. Francisco Morás. Petrópolis, RJ: Vozes, 2013. 174p.

FERREIRA, Maria Cristina Leandro. O corpo como materialidade discursiva. Vitória da Conquista: REDISCO, v. 2, n. 1, 2013, p. 77-82.

FOUCAULT, Michel. História da Sexualidade 1: a vontade de saber. Trad. Maria Thereza da Costa Albuquerque e J. A. Guilhon Albuquerque. 13a edição. Rio de Janeiro: Edições Graal, 1999. 155 p.

Os anormais: curso no Collège de France (19741975). Trad. Eduardo Brandão. São Paulo: Martins Fontes, 2001.

Aula de 17 de março de 1976. In: . Em defesa da sociedade: cursos no Collège de France (1975/1976). Trad. Maria Ermantina Galvão. 4a ed. São Paulo: Mantins Fontes, 2005a, p. 285-315.

História da sexualidade 3: o cuidado de si. Trad. Maria Thereza da Costa Albuquerque. $8^{\mathrm{a}}$ edição. Rio de Janeiro: Edições Gaal, 2005b. 246 p.

A vida dos homens infames. In: Estratégia, Poder-Saber. Trad Vera Lucia Avellar Ribeiro. 2a ed. Rio de Janeiro: Forense Universitária, 2006 (Ditos \& Escritos IV), p.203-222.

A arqueologia do saber. Trad. Luiz Felipe Baeta Neves. $7^{a}$ edição. Rio de Janeiro: Forense Universitária, 2008. 236 p.

Governamentalidade. In: MACHADO, Roberto (org.). Microfísica do Poder. 26a edição. São Paulo: Graal, 2013a, p. 407-431.

Sobre a história da sexualidade. In: MACHADO, Roberto (org.). Microfísica do Poder. 26a edição. São Paulo: Graal, 2013b, p. 363-406.

GREGOLIN, Maria do Rosário. Foucault e Pêcheux na análise do discurso: diálogos e duelos. São Carlos: Claraluz, 2004.

Análise do discurso e mídia: a (re)produção de identidades, São Paulo: comunicação, mídia e consumo. v. 4, n. 11, 2007, p.11- 25.
. J. J. Courtine e as metamorfoses da análise do discurso: novos objetos, novos olhares. In: GREGOLIN, Maria do Rosário; SARGENTINI, Vanice (Orgs.). Análise do discurso: heranças, métodos e objetos. São Carlos. Editora Claraluz, 2008a, p. 21-36.

Identidade: objeto ainda não identificado? Vitória da Conquista: Estudos da Língua(gem). v. 6, n. 1, 2008b, p. 81-97.

GUILHAUMOU, Jacques; MALDIDIER, Denise. Efeitos do arquivo. A análise do discurso no lado da história. In: ORLANDI, Eni Puccinelli (Org.) [et al]. Gestos de leitura: da história no discurso. $3^{\mathrm{a}}$. ed. Campinas: editora da Unicamp, 2010, p. 161-183.

HARDT, Michael; NEGRI, Antonio. Império. Trad. Berilo Vargas. Rio de Janeiro: Record, 2001.

LE GOFF, Jacques. A história do quotidiano in DUBY, G; ARIÈS, P; LADURIE, E. L. R; LE GOFF, J. História e nova história. Trad. Carlos da Veiga Ferreira. $3^{\text {a }}$ ed. Lisboa: Editorial Teorema, 1994. p. 87-96.

MILANEZ, Nilton. As aventuras do corpo: dos modos de subjetivação às memórias de si em revista impressa. Tese (Doutorado), pelo Programa de pós-graduação em Linguística e Língua Portuguesa, da Faculdade de Ciências e Letras de Araraquara, da Universidade Estadual Paulista Júlio de Mesquita Filho, Araraquara, 2006. $210 \mathrm{f}$

Corpo cheiroso, corpo gostoso: unidades corporais do sujeito no discurso. Maringá: Acta Scientiarun. LanguageandCulture, v. 31, n. 2, 2009, p. 215-222.

Discurso e imagem em movimento: o corpo horrorífico do vampiro no trailer. São Carlos: Claraluz, 2011.

MONTEIRO, Maria Emanuele Rodrigues. Governamentalidade, biopolítica e biopoder: a produção identitária para o corpo velho nos discursos da mídia brasileira contemporânea.Tese (Doutorado), pelo Programa de Pós-graduação em Linguística, do Centro de Ciências Humanas Letras e Artes, da Universidade Federal da Paraíba. João Pessoa, 2014. $240 f$.

PÊCHEUX, Michel. A análise do discurso: três épocas (1983). Trad. Jonas de A. Romualdo. In: GADET, Françoise; HAK, Tony (orgs.). Por uma análise automática do discurso: uma introdução à obra de Michel Pêcheux. Trad. Bethania S. Miriani [et al.] Campinas: Editora da UNICAMP, 1990, p. 311-319.

. O discurso: estrutura ou acontecimento. Trad. Eni Puccinelli Orlandi. 4a edição. Campinas, SP: Pontes Editores, 2006.

SANTOS, Keula Aparecida de Lima. Um olhar sobre os espaços de "Perfecto Luna": imagens do medo e da 
146 Claudemir Sousa and Regina Baracuhy, Biopolítica, biopoder e cuidado de si na campanha antitabagista...

morte in MILANEZ, Nilton; PESSOA-BRAZ, Analiz; GAMA-KHALIL, Marisa Martins. Outros corpos, espaços outros. Vitória da Conquista: Labedisco, 2014, p. 120-136.

Recebido em: 05/06/2015

Aceito em: 23/07/2015 